\title{
Government regulation and public opposition create high additional costs for field trials with GM crops in Switzerland
}

Journal Article

Author(s):

Bernauer, Thomas; Tribaldos, Theresa; Luginbühl, Carolin; Winzeler, Michael

Publication date:

2011-12

Permanent link:

https://doi.org/10.3929/ethz-b-000026022

Rights / license:

In Copyright - Non-Commercial Use Permitted

Originally published in:

Transgenic Research 20(6), https://doi.org/10.1007/s11248-011-9486-x 


\title{
Government regulation and public opposition create high additional costs for field trials with GM crops in Switzerland
}

\author{
Thomas Bernauer • Theresa Tribaldos • \\ Carolin Luginbühl $\cdot$ Michael Winzeler
}

Received: 4 December 2010/Accepted: 17 January 2011 / Published online: 30 January 2011

(C) Springer Science+Business Media B.V. 2011

\begin{abstract}
Field trials with GM crops are not only plant science experiments. They are also social experiments concerning the implications of government imposed regulatory constraints and public opposition for scientific activity. We assess these implications by estimating additional costs due to government regulation and public opposition in a recent set of field trials in Switzerland. We find that for every Euro spent on research, an additional 78 cents were spent on security, an additional 31 cents on biosafety, and an additional 17 cents on government regulatory supervision. Hence the total additional spending due to government regulation and public opposition was around 1.26 Euros for every Euro spent on the research per se. These estimates are conservative; they do not include additional costs that
\end{abstract}

T. Bernauer $(\bowtie) \cdot T$. Tribaldos

ETH Zurich, Center for Comparative and International

Studies and Institute for Environmental Decisions,

Haldeneggsteig 4, 8092 Zurich, Switzerland

e-mail: thbe0520@ethz.ch

T. Tribaldos

e-mail: theresa.tribaldos@ir.gess.ethz.ch

C. Luginbühl · M. Winzeler

Agroscope/Forschungsanstalt Agroscope Reckenholz-

Tänikon ART, Reckenholzstrasse 191, 8046 Zürich,

Switzerland

e-mail: carolin.luginbuehl@art.admin.ch

M. Winzeler

e-mail: michael.winzeler@art.admin.ch are hard to monetize (e.g. stakeholder information and dialogue activities, involvement of various government agencies). We conclude that further field experiments with GM crops in Switzerland are unlikely unless protected sites are set up to reduce these additional costs.

Keywords Genetically modified plants · Field trials · Costs $\cdot$ Regulation $\cdot$ Public opposition
Abbreviations
GM Genetically modified
ART Agroscope Reckenholz-Täniken
ACW Agroscope Changins-Wädenswil
SNSF Swiss National Science Foundation
NRP National Research Program
FOEN Federal Office for the Environment

\section{Introduction}

Genetically modified (GM) crops are controversial in Switzerland, as they are in most other European countries. In 2005, Swiss voters decided to enact a five-year moratorium on commercial cultivation of GM crops. This moratorium was due to end in 2010, but was recently extended until late 2013. Scientific research, including field experiments with GM plants, is exempt from the moratorium. Most proponents of the 
Table 1 Size (in $\mathrm{m}^{2}$ ) and location of GM field trials

\begin{tabular}{llll}
\hline & 2008 & 2009 & 2010 \\
\hline GM wheat, ART & 400 & 555 & 805 \\
Total area, ART & 5,000 & 8,700 & 7,200 \\
Ratio of GM/non-GM & $\mathbf{0 . 0 8}$ & $\mathbf{0 . 0 6}$ & $\mathbf{0 . 1 1}$ \\
GM wheat, ACW & - & 271 & 271 \\
Total area, ACW & - & 947 & 947 \\
Ratio of GM/non-GM & - & $\mathbf{0 . 2 9}$ & $\mathbf{0 . 2 9}$ \\
\hline
\end{tabular}

Agroscope Reckenholz-Tänikon (ART) is located near Zurich $\left(47^{\circ} 25^{\prime} 44.20^{\prime \prime} \mathrm{N} / 8^{\circ} 30^{\prime} 58.87^{\prime \prime} \mathrm{E}\right)$. The GM field trial of Agroscope Changins-Wädenswil (ACW) is located in Pully near Lausanne $\left(46^{\circ} 30^{\prime} 35.21^{\prime \prime} \mathrm{N} / 6^{\circ} 39^{\prime} 42.28^{\prime \prime} \mathrm{E}\right)$. For scientific reasons (e.g. comparison with conventional varieties, surrounding experiments with a border crop) each field trial includes a large proportion of non-GM plots

The values are given in bold for better distinction of the two locations and for highlighting the ratios compared to the areas

moratorium - and of course also the opponents of the moratorium - in fact believe that scientific research on GM plants should continue in the moratorium period to clarify the benefits and risks of GM crops. They expect that such research will help voters and policy-makers make a well-reasoned choice on what should happen after the moratorium ends.

As part of this process, Switzerland's government asked the Swiss National Science Foundation (SNSF) to implement a research program on the benefits and risks of GM plants (National Research Program, NRP 59, http://www.nfp59.ch). This research, which started in June 2007 and will end in 2012, includes field trials with powdery mildew (fungal) resistant GM wheat lines in two locations. Table 1 indicates the size and location of these field trials.

The field trials at the first location started in spring 2008 and were concluded in autumn 2010. Those at the second location started 1 year later, in spring 2009 , because of an (eventually unsuccessful) appeal by opponents to the Swiss Federal Administrative Court $^{1}$ and were concluded in autumn 2010 as well.

\footnotetext{
${ }^{1}$ The plaintiffs challenged the field trial permit by the FOEN (Swiss Federal Office for the Environment) on procedural grounds, claiming that the step-by-step approval process required by law was not properly implemented. The court approved the plaintiffs' request to delay the beginning of the field trial until the court had decided. However, the court eventually decided against the plaintiffs, judging that the approval procedure had been correctly implemented. But the court decision came too late for the field trial to start as planned.
}

The purpose of these field trials is to examine whether GM wheat lines that are resistant against powdery mildew infections in the lab have this capacity also under natural conditions; and whether negative effects in terms of reduced crop performance or biosafety risks occur. The biosafety part of the field trials focuses on interactions of GM wheat lines with the environment, other plants, and non-target organisms. (http://www. konsortium-weizen.ch/).

Compared to the very few field trials with GM plants in Switzerland prior to the NRP 59, the recent field trials are larger in scale; and they involve several research projects carried out by different teams but managed by a coordinating committee of scientists. Moreover, in contrast to previous field trials, they are carried out as part of a larger research activity under a formal mandate by the Swiss government and in the context of the new Swiss Gene Technology Law and the revised Release Ordinance.

How easy (or difficult) is it for scientists to carry out field trials with GM plants under specific social and political or regulatory conditions? We argue that an estimate of costs can provide a reasonably good answer. Hence we have examined the costs of the Swiss GM plant field trials.

\section{Additional costs due to government regulation and public opposition}

We are interested primarily in those costs that have materialized above and beyond the standard costs of conducting field trials with GM plants. The benchmark for those additional costs is the basic research costs that would arise in the absence of any legal and regulatory constraints and public opposition. Most countries worldwide have established some regulation for GM plants, and some opposition to GM plants exists in most countries that allow commercial cultivation of and/or scientific field experiments with GM crops. Hence the benchmark of no regulation and no public opposition is somewhat artificial. Nor may such a situation be desirable. However, we use this benchmark because it avoids any normative judgements about how much regulation is appropriate or necessary, and in what form, and how much public opposition is useful or legitimate. We return to this issue in the discussion section at the end of the paper. 
In brief, we are primarily interested in estimating the additional costs that arise from government regulation and public opposition to field trials with GM plants. Whether these additional costs are too high, too low, or appropriate is a normative question that must be answered by policy-makers, scientists interested in such field trials, research funding agencies, and society as a whole.

A rigorous estimate of additional costs would require an experiment in which otherwise identical field trials are carried out in two different settings, one with current Swiss levels of regulation and public opposition, the other in the absence of any government regulation and public opposition (holding all other determinants of costs constant). This is obviously not possible. However, the second best approach is to isolate those costs that, with high probability, would not have materialized in the absence of government regulation and public opposition.

To identify those additional costs we have examined the expenditures for the two field trials, from the preparation to the decommissioning stage. Figure 1 summarizes the results.

Expressed as ratios, which allow for comparison in any currency: for every Euro or US Dollar spent on the research per se, an additional 78 cents were spent on security, an additional 31 cents on biosafety, and an additional 17 cents on government regulatory supervision. Thus, total additional spending due to government regulation and public opposition was in the order of 1.26 Euros for every Euro spent for the research per se. In other words, these field trials with GM plants in Switzerland have cost more than twice of what they would have cost in the absence of government regulation and public opposition.

Table 2 reports more detailed figures. The lion's share of additional costs incurred during the preparation phase concerns the approval process. Those costs were borne mainly by the applicants' (ETH Zurich (http://www.pb.ethz.ch/) and University of Zurich (http://botserv1.uzh.ch/home/bkeller/), ART (http://www. agroscope.admin.ch/org/00275/), ACW (http://www. agroscope.admin.ch/org/00273/)) institutions and the FOEN.

Following a recommendation by the FOEN, the applicants submitted three separate requests for field trials to the FOEN. Two of these dealt with different wheat lines, the third concerned an experiment with a hybrid of wheat and goat grass (Aegilops cylindrica). The applications were, in principle, for 3 years, but each field trial still needed specific authorization for each season. In other words, the approval procedure for the field trials of the so called wheat consortium (http://www.konsortium-weizen.ch/) involved three separate approval processes, with two additional authorizations required for the second and third of the

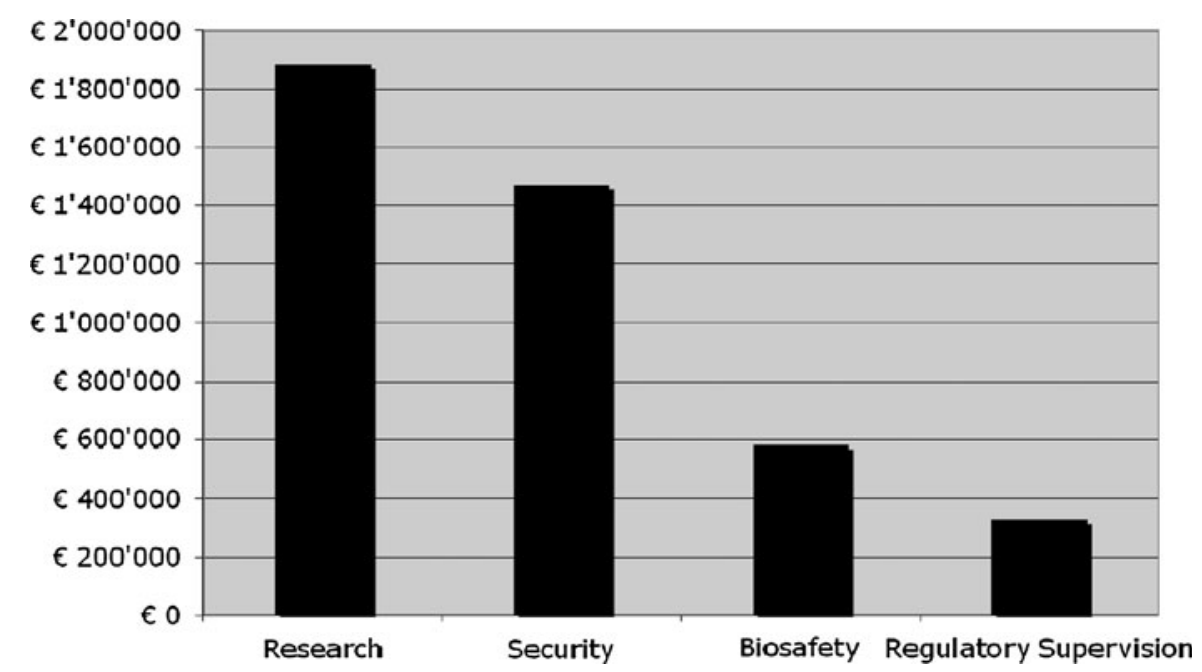

Fig. 1 Total spending for research, security, biosafety, and regulatory supervision. Notes Spending on security has served to protect the field trials from acts of vandalism, the key threat emanating from public opposition. Biosafety expenses are largely due to government regulation. Costs for regulatory supervision are estimates of what the Swiss Federal Office for the Environment (FOEN) spent for dealing with the field trial applications and supervising the implementation of the trials 
Table 2 Estimates of additional costs

\begin{tabular}{lr}
\hline Type of cost & \multicolumn{1}{l}{$\begin{array}{l}\text { Cost in } \\
\text { Euros }\end{array}$} \\
\hline Application for and preparation of field trials & $\begin{array}{r}\text { 254,000 } \\
88,000\end{array}$ \\
Legal expenses related to obtaining approval for & \\
$\quad$ the trials & $1,384,000$ \\
Security costs (for both sites, Reckenholz and & \\
$\quad$ Pully) & 584,000 \\
Biosafety (for both sites, Reckenholz and Pully) & 57,000 \\
Decommissioning stage & $2,367,000$ \\
\hline Total &
\end{tabular}

three growing seasons at Reckenholz and one additional authorization for Pully. Two additional elements of complexity were that two universities (ETH Zurich, University of Zurich) were involved, and the experiments took place in two different regions of the country. The latter implicated distinct stakeholder information/consultation processes (these are required by law) and submission of the applications in German and French.

The FOEN, according to its own estimates, has incurred costs in the order of 329,000 EUR, primarily in the form of personnel expenses, for handling the entire research program. ${ }^{2}$ It was not possible to separate the expenses between the preparation and implementation phase. However, the bulk of the expenses materialized during the preparation phase. Besides staff work time for evaluating the applications, considerable work time went into handling of petitions against the field trials and a legal case that was launched by opponents against the FOEN's decision to permit the experiments in Pully. Some other parts of the federal administration were involved in the process as well, ${ }^{3}$ though the FOEN was the lead agency for these field trials. However, it was not possible to obtain any reliable information on the financial implications for government bodies

\footnotetext{
2 This part of the data collection and cost estimation was carried out by Dr. Hans Hosbach from FOEN.

${ }^{3}$ E.g. the Federal Office for Agriculture (FOAG), the Federal Office of Public Health (FOPH), the Office for Waste, Water, Energy and Air (AWEL) of the Canton of Zurich, the Office for the Environment and Energy of the Canton of Vaud (SEVEN), the Federal Committee for Biosafety, and the Federal Ethics Committee on Non-Human Biotechnology.
}

other than the FOEN. Rough estimates by the FOEN are in the order of 7,300-73,000 EUR, but we do not include such costs in our estimate.

The wheat consortium, in particular the groups from the University of Zurich, ETH Zurich, ACW, and ART, who carried out the field experiments, spent around 254,000 EUR to prepare the applications. This amount includes staff salaries for preparing the applications (documents of several hundred pages) and revising them according to follow-up requests by the FOEN. It also includes biosafety expenses associated with preparing the seeds, testing of the plant material, elaborating a biosafety emergency plan for the field trial, and an application fee of 13,000 EUR charged by the FOEN. ${ }^{4}$

The most important additional cost items were security and biosafety expenses. Initial security measures included a single fence and, during the growing season, a security guard at night and on weekends. They also included permanent video surveillance. After an attack by radical GMO opponents in June 2008, in which a major part of the field trial in Reckenholz was damaged, a new security concept was developed. A three-meter-spaced double fence with barbwire on top and a motion sensor at the outer fence were installed. Moreover, the security guard presence was extended to $24 \mathrm{~h}$ (one security guard with a specially trained dog at any point in time during the growing season). Figure 2 shows the entrance to the field at the ART site with the double fence in place.

These additional measures were put in place at both sites (ART and ACW). Two minor attacks on the site in Pully (ACW) took place in 2009 and 2010, when offenders tried to spray herbicides over the fences.

\footnotetext{
4 The application fees charged by the FOEN were funded by the SNSF, the remaining expenses by the applicants' institutions. The production of the GM seeds took around 15 months and cost around 100,000 EUR (including the gardener, energy in the greenhouse, soil, fertilizer, and plant protection products, and infrastructure). We include these costs in our estimate because the seed production in the greenhouse as required by the FOEN is much more expensive than the usual seed production in the field (without any regulatory restrictions it would have cost no more than around 3,700 EUR to produce the seeds). Salaries of scientists are not included in the mentioned amounts. The translation of the applications into German and French is not included in our cost estimates because we could not reliably estimate the total work time and costs of this activity.
} 


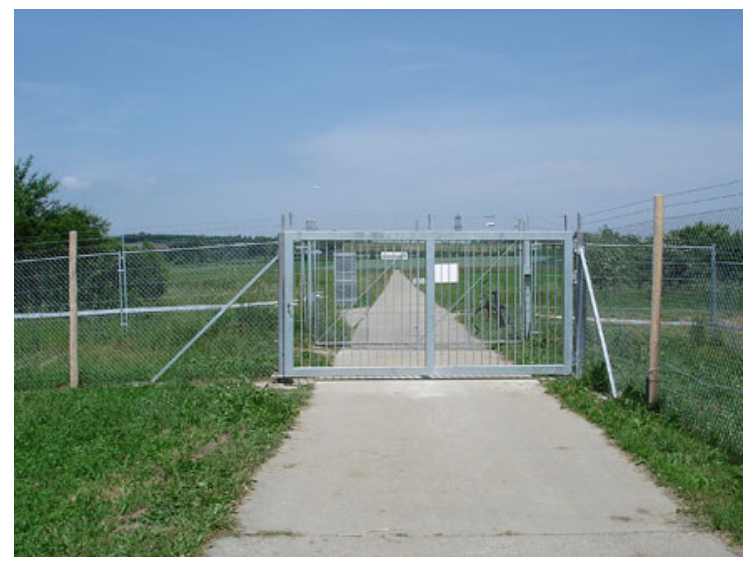

Fig. 2 Gate to the field

However, the field trials were left undamaged. A specialist of the Swiss Federal Police provided advice throughout the field trial period, but this work is difficult to monetize and is not included in our estimate.

The SNSF initially granted 730,000 EUR for security measures and the organization of the overall project (the latter consists of 8 individual research projects). After the attack in June 2008, the State Secretariat for Education and Research (SER), which funds the NRP 59 via the SNSF, added another 1.46 million EUR to the budget to fund additional security measures. By January 2010, the SNSF had transferred 1.552 Mio EUR for security measures at the two sites, of which the ART site received 910,000 EUR and the ACW site 642,000 EUR. Legal proceedings concerning the approval process generated costs in the order of 88,000 EUR. These are included in the above mentioned amount. ${ }^{5}$

\footnotetext{
5 The initial security installation costs at the ART field were around 275,000 EUR, of which 248,000 EUR were paid by the SNSF and 27,000 EUR were paid by ART. In 2008 and 2009, the operational expenses for security were 335,000 and 307,000 EUR respectively, paid by the SNSF. The cost for the security guard (168'000 EUR) took up the largest part of the security costs, followed by the enhancement of the infrastructure for surveillance of the field $(146,000$ EUR in 2009). Accordingly, the security costs in 2010 were around 186,000 EUR. The damage inflicted by the attack in 2008 at the ART field was in the order of 183,000 EUR, measured by what it would have cost to set up the field experiment again. However, some of the scientists involved decided not to repeat the first trial year at Reckenholz. Hence we do not include these costs. The site in Pully spent 193,000 EUR for the security guard and around 80,000 EUR for the initial installation of the security infrastructure and its maintenance.
}

Biosafety, in this context, aims primarily at protecting the surrounding environment from the unintended diversion and outcrossing of GM plants. The FOEN's approval of the field trials requested specific distances between the trial plots and adjacent fields with conventional crops. Other measures included bird protection nets, mini plots in the surrounding environment for measuring outcrossing, very strict harvesting rules, and a GIS specialist who had to map the locations of the GM crops in detail. Outcrossing tests had to be conducted during each trial season to establish the distance in which outcrossing of GM wheat within the border crop, a physical pollen barrier around the field trials, occurs. Another large share of biosafety measures concerns communication with neighboring farmers for coordinating the crop rotation. This was necessary to ascertain the required safety distances between GM and conventional wheat.

Biosafety-related costs at Reckenholz have been around 99,000 EUR per year, of which approximately $85 \%$ was paid for by the SNSF. The personnel costs for organizing and conducting the outcrossing tests account for the largest share (around 58,000 EUR). Bird nets, the surrounding planting, GIS work, the communication work, and harvesting costs amount to the remaining 41,000 EUR. Figure 3 shows part of the harvesting process. Biosafety expenditures at Pully have been in the order of 2,300 EUR per year for monitoring the neighborhood and between 7,300 and 11,000 EUR per year for outcrossing tests. Because the site in Pully is surrounded by residential areas rather than agriculture it was not necessary to set up and monitor mini plots. However, birds appear to be more active in Pully, so it was necessary to install bird nets for around 3,300 EUR. ${ }^{6}$

During the decommissioning phase, the security installations of both sites need to be removed after the field trial — though there currently is some discussion on whether to leave them in place for potential future GM

\footnotetext{
Footnote 5 continued

Personnel costs for technical coordination of biosafety and security amounted to 69,000 EUR in Reckenholz and 70,000 EUR in Pully.

${ }^{6}$ If infrastructure costs are added, a 6 months field trial with GM wheat costs around 365,000 EUR in the cases examined, including all security and biosafety measures. Because expenses for the security guard make up the largest share of the security costs, the total amount would increase if other GM crops with a longer growth period were tested in the field.
} 


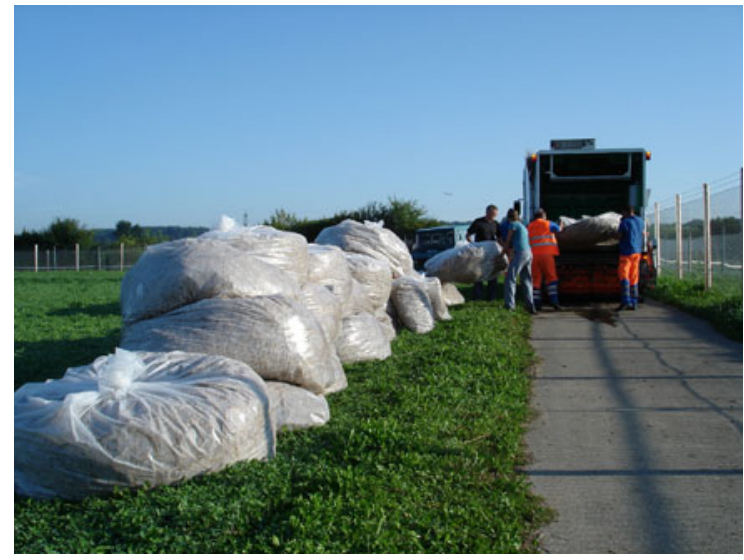

Fig. 3 Removal of spare plant material after harvesting. Note Due to government regulation, all spare plant material had to be separated and collected for incineration

crop field trials. Moreover, the FOEN approval of the field trials includes the obligation to make sure that no volunteer GM wheat can grow on the respective fields after the trials are completed. Hence, the FOEN requires monitoring of the site for 2 years after completion of the field trial. In each of those 2 years, the site has to be checked for the presence of wheat or goat grass plants; all seedlings emerged must be collected, analysed for the presence of the bar gene and burned. If a transgenic plant is found it has to be reported to the FOEN. There is no budget for the monitoring phase. Consequently, this work will have to be done by employees from Agroscope, ETH Zurich and University of Zurich using the regular budget of these institutions. The costs during the monitoring phase are impossible to estimate at the moment because they depend very much on the amount of GM seedlings. With a small number or no seedlings these costs will be minor. The budget for the decommissioning of the technical installations, on the other hand, is around 47,000 EUR in Reckenholz and around 10,000 EUR in Pully.

Figure 4 shows the development of additional costs over time, from the preparation to the decommissioning phase, itemized by research, security, biosafety, and regulatory supervision. Figure 5 shows shares in total costs by source of funding.

\section{Discussion}

Our estimates are conservative; that is, they are likely to underestimate total additional costs. The main

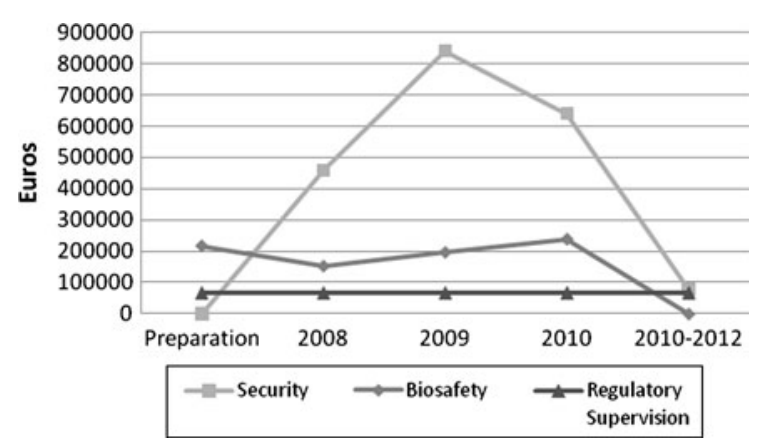

Fig. 4 Additional costs over time

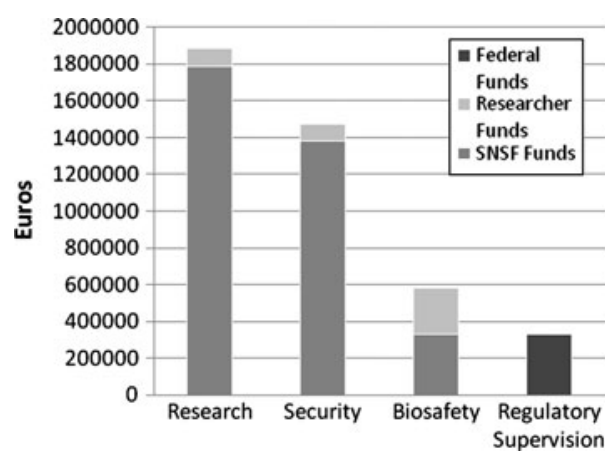

Fig. 5 Spending by institution

reason is that some types of costs that are difficult to quantify reliably are not included, even though they appear to be caused to a large degree by government regulation and public opposition. Examples include stakeholder information and dialogue activities (e.g. information events and open days for farmers and the general public), which at least to some extent are also required by the Swiss Gene Technology law. Other costs not considered include the SNSF staff time for dealing with public relations issues, stakeholders, and policy-makers-such expenses have been considerably higher for the NRP 59 than for other National Research Programs. Yet other costs we did not include concern the involvement of government bodies other than the FOEN, translation of applications into French and German, and damage caused by vandalism (see above).

Whether one regards the additional costs of field trials with GM plants, as estimated above, as acceptable, excessive, or appropriate depends, of course, on one's views on the benefits and risks of 
GM plants. ${ }^{7}$ GMO skeptics are likely to view these costs as necessary and acceptable, GMO enthusiasts as excessive. Radical opponents of GM plants will probably consider any public spending on such research a waste of money.

Our aim is not to take sides in this controversy, but to offer a quantative assessment of the implications of existing regulation and public opposition for field trials with GM plants. However, one of the key issues in this context is whether Swiss funding agencies will in future be willing to pay additional costs in the same order of magnitude as in the NRP 59 program, and whether Swiss scientists will be willing to engage in field trials under such conditions or will carry out such work in other countries.

The latter point raises the question of how the estimated additional costs in Switzerland compare to those in other countries. Unfortunately, there is no comparable data, though the ratio of additional costs to basic research costs in the Swiss field trials is almost certainly much higher than in the case of field trials in countries such as China or the United States, where public opposition against GM-crops is less pronounced and government regulation of field trials is less onerous. ${ }^{8}$ Our approach could in fact be used to estimate the additional costs of field trials with GM crops in a wide range of countries to provide a systematic comparison of the conditions under which such scientific research takes place.

Which of the two types of constraints on field trials with GM plants, government or society, is more important quantitatively cannot be established reliably with our data. The reason is that clear-cut separation of costs due to government regulation from those due to public opposition is virtually impossible in at least two respects. Government rules in Switzerland (and also in many other countries) require public information on the exact location of a field trial. This, in turn, makes field trials an easier target for attacks by radical GM plant opponents,

\footnotetext{
7 The field trials and their results may, of course, also change public perceptions of the benefits and risks of GM plants. However, such effects are longer-term and cannot be quantified for the time being.

${ }^{8}$ Further analysis should focus both on basic research costs and additional costs and distinguish countries in which both types of costs are similar and low or similar and high. While the ratio would in both cases be similar or even identical, the underlying cost structures could differ very strongly.
}

which in turn leads to more spending on security measures. Moreover, government regulation requiring certain biosafety measures is at least in part a consequence of public concerns about the environmental and health implications of GM plants. This difficulty of separating regulatory from social implications does, however, not affect the overall estimate of additional costs.

Finally, our analysis points to measures that could reduce the additional costs of field trials quite dramatically. Arguably the most important such measure is the establishment of protected sites that are open to all research groups conducting publicly funded field trials. Setting up one or more such sites in Switzerland would require up front investments in the order of $€ 730,000-1,460,000$ for fences and electronic surveillance. ${ }^{9}$ In contrast to the current arrangement, however, this investment would not be lost after a few field trials. Such an arrangement could also reduce operational expenses, notably $24 \mathrm{~h}$ security guards, which accounted for a large share of the security expenses. To the extent a field trial site could be used over many years, larger up front investments in infrastructure-based security measures would be cheaper in the long run than security guards.

Besides this potential for major, direct reduction of additional costs, compliance related administration and security costs may have scale effects and may be reduced as a result of learning processes. This means that with expanding numbers and sizes of field experiments, scientists are likely to become more efficient in handling biosafety and security challenges; and government authorities are likely to become more efficient in handling applications for field trials and supervising their implementation.

Without major cost reductions it appears unlikely that further field trials with GM plants will take place in Switzerland. GM plants with a wide range of potential attributes as well as plants produced by other novel genetic and other technologies are currently developed by scientists. The implications of not being able to independently field test these new plants in Switzerland need to be carefully considered by policy makers.

Acknowledgments We are very grateful for the support of the National Research Program NRP 59 "Benefits and Risks of

$\overline{9}$ Based on estimates by Agroscope. 
the Deliberate Release of Genetically Modified Plants" of the Swiss National Science Foundation and to Detlef Bartsch, Dirk Dobbelaere, Beat Glogger, Willy Gruissem, Hans Hosbach,
Stefan Husi, Beat Keller, Fabio Mascher, Pia Malnoe, Jules Pretty, Jeremy Sweet, and Claudia Zwahlen for valuable comments on previous versions of this paper. 